\title{
Amnion grafting in vaginoplasty
}

\author{
Prof (Dr) Hem Kanta Sarma
}

\author{
Correspondence: Prof (Dr) Hem Kanta Sarma, Professor \& HOD, Department of Obstetrics \\ \& Gynaecology, Jorhat Medical College, Jorhat, Assam, India; \\ Email - sarmahemkanta@gmail.com
}

Distributed under Attribution-Non Commercial-ShareAlike 4.0 International (CC BY-NC-SA 4.0)

\begin{abstract}
Absent vagina (both complete and partial) is often encountered by the gynaecologists as a case of amenorrhoea or as a case of post marital problem due to sexual dysfunction. These problems are usually due to dysgenesis of mullerian ducts (eg. MRKH syndrome) or disorders of vertical fusion of the mullerian ducts. In the later group, some cases are having partial canalisation of the vagina, others complete non-canalisation of the vagina; some patients also have non canalised cervix (dysgenesis of cervix).
\end{abstract}

Vaginal atresia has an incidence of 1:4000 to $1: 10,000^{1}$. For the treatment of these patients a neovagina is to be created by surgical dissection and to maintain the neovagina a mould is to be kept in place along with grafting of the raw area of the neovagina. For this grafting various tissues have been used for last 100 years. Grafting materials used are as follows - skin, bucccal mucosa, amnion, peritoneum, oxidised regenerated cellulose. All these graft materials has merits and demerits. Amnion is considered to be one of the best for this purpose, as it is cost effective, non immunogenic, with less side effects and effective.

Historical background: Surgical correction of vaginal agenesis has long history of evolution as summarised below-

1907 - Baldwin used double loop of ileum for covering the neovagina.

1910 - Popaw used the rectum mobilised anteriorly to cover the raw area of newly created vagina.

1911 - Schubert modified the Popaw's method.

1938 - Wharton, in Johns Hopkins used a balsa form covered with a thin rubber sheath to dilate the newly created vagina.

1948 - Counseller's reported 100 cases from Mayo's clinic with encouraging results.
1950-1989 - Mc Indoe used skin graft in Johns Hopkins Hospital in 94 patients with $83 \%$ success rate. He used foam rubber form as mould.

Amnion as a graft: Amnion is non immunogenic and has been shown to reduce inflammation and pain. It serves as a matrix for cell deposition. The amniotic membrane contains the following : growth factors, cytokines, vascular endothelial growth factors, platelet derived growth factors $\mathrm{AA}$ and $\mathrm{BB}$, transforming growth factors alpha \& beta, basic fibroblast growth factor, epidermal growth factor, granulocyte - colony stimulating factor and interleukins 4,6,8 and 10. Amnion consists of 5 layers ( 0.02 to $0.05 \mathrm{~mm}$ thick), they are as follows: epithelium, basement membrane, compact layer, intermediate layer and fibroblast (figure 1). It does not have any blood vessel. Chorion is 4 times thicker

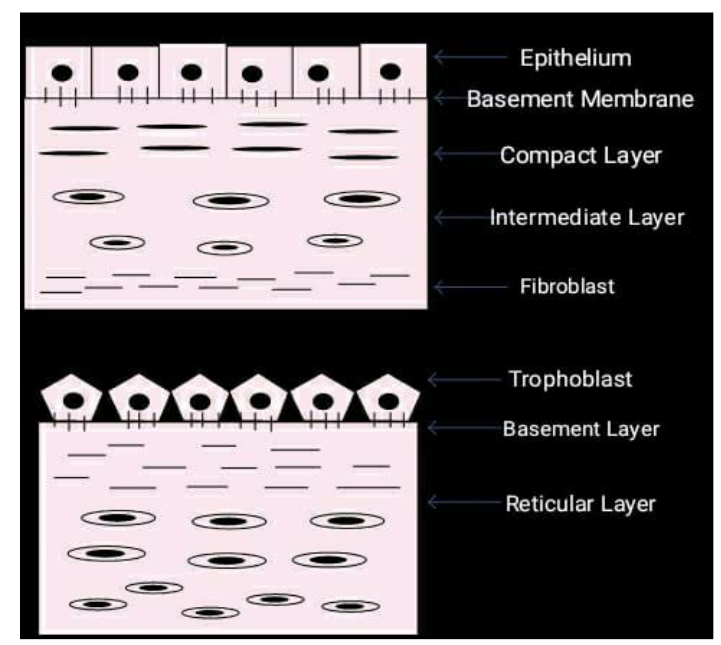

Figure 1: Diagrammatic representation of amnion and chorion. 
than amnion, contains a reticular layer and trophoblast besides a basement membrane.

Amniotic membrane is considered a useful material for grafting the artificially created vagina for the following reasons:

i) It facilitates migration of epithelial cells.

ii) It reinforces basal cells adhesion.

iii) It promotes epithelial differentiation.

iv) It prevents epithelial apoptosis.

v) It Promotes epithelialisation in healing of the wounds.

vi) Good permeability of basement membrane of amnion facilitates good oxygenation of epithelial cells.

Procedure: In vaginoplasty, a careful dissection by sharp and blunt approach is necessary to create a neovagina in between urethra and anal canal taking utmost care not to injure urethra, bladder and rectum. A soft mould is prepared by putting some cotton wool balls in a condom. A patch of amnion is retrieved from the after births of a recently delivered patient (preferably caesarean section - without any potential infection and properly screened patient for all relevant viral markers). The amnion is kept in normal saline after properly cleaning of the blood, clots, etc. The soft mould already prepared is covered by the amnion patch and put gently into the newly created vagina.

The vaginal introitus is closed with few interrupted ethilon sutures. A catheter is kept indwelling. The mould is kept for 10 days; then the vagina is irrigated with betadine solution gently for 2-3 days. Again a soft mould is used to dilate the vagina intermittently by the patient herself under

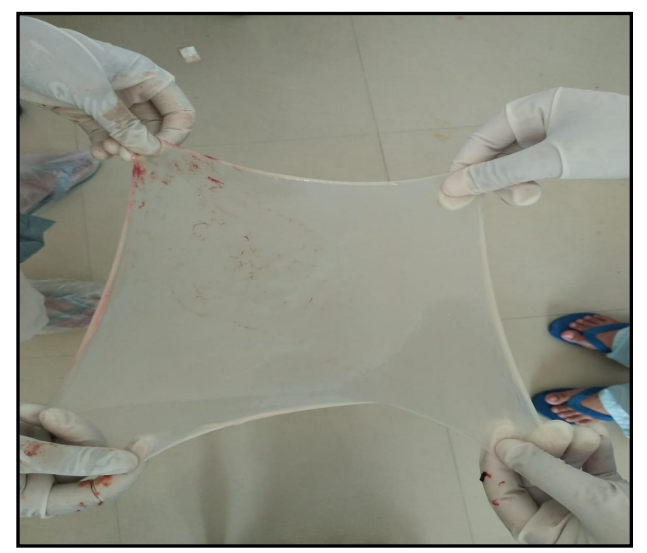

Figure 2: Showing the amnion prepared for grafting. supervision. Gradually she learns it and then allowed to go home to continue repeated self dilatation of the newly created vagina for one month. She comes for review after one month. At that time the vaginal integrity is reassessed. If necessary dilatation under anaesthesia is carried out and repeated self dilatation is advised.

Experience of the author: Since 1992, December to 2019, December, the author himself had operated 14 patient of vaginal agenesis (out of these 4 had MRKH syndrome, rest 10 cases of vertical fusion defect) by modified Mc Indoe's technique using freshly harvested amnion as a graft (figure 2 ). In this series the author observed very encouraging results with more $92.8 \%$ structural correction and $85 \%$ functional correction at the end of 1 year follow up. Few patients could be followed up for long period; 2 of them reported with successful married life with successful

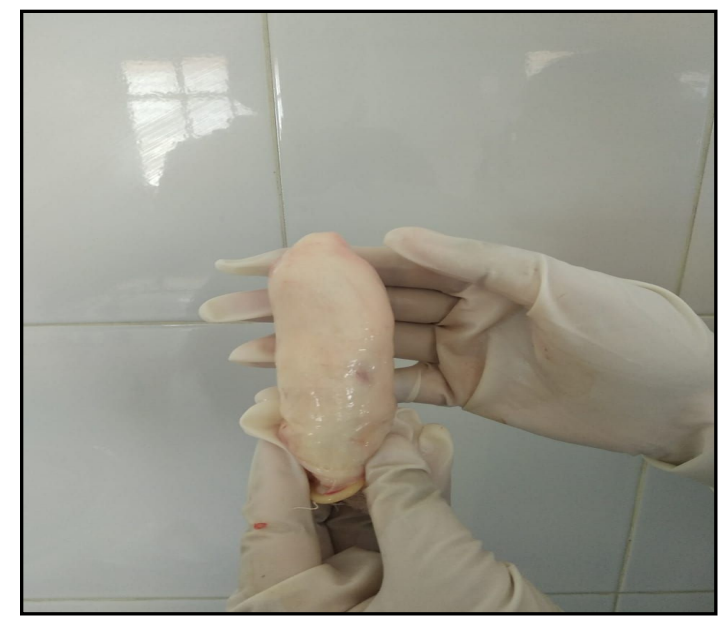

Figure 3: Showing the mould wrapped with amnion graft

pregnancies. Complications of the procedures were mostly recurrent stenosis which needed recurrent dilatation, dilatation under general anaesthesia or repeat surgery with grafting. Result of the first attempt was most encouraging.

Out of these 14 patients, in 5 patients, there were cervical dysgenesis for which, the author had to approach through the abdominal route along with vaginal dissection, uterus was opened, the lower pole of the uterine cavity was located and with the help of a guiding probe from below we made a nick was made on the thick tissues of that site by sharp dissection so that a communication is created between the uterine cavity and the vagina. A $14 \mathrm{G}$ foley's catheter is was kept in uterine cavity whose balloon was inflated by $5 \mathrm{cc}$ normal 
saline after taking the bites on the $1^{\text {st }}$ layer of uterus. Uterus was closed in 3 layers. Vaginal mould with graft was kept fixed in vagina for 10 days (figure 3). Vaginal introitus was closed by interrupted sutures. The intrauterine foley's catheter was kept for 20 days (figure 4). Patient was encouraged to mobilize from $3^{\text {rd }}$ day, urethral catheter withdrawn and put on normal diet.

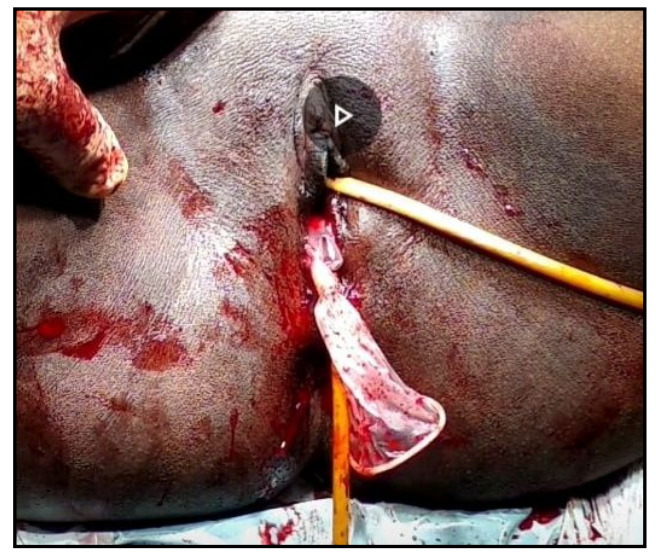

Figure 4: At the end of the procedure with the mould with amnion grafts in neovagina along with an intrauterine catheter.

Discussion

Tancer and associates reported good results with amnion grafting ${ }^{2}$. Karjalainen et al states that results of amnion grafting for surgical treatment of vaginal agenesis were more physiological ${ }^{3}$. Sarwar I et al used amnion grafting for 28 patients in 20 years with encouraging results; of course they had a case of rectal injury; they found it acceptable both sexually and aesthetically ${ }^{4}$. Kathpalia SK et al observed good epithelialization after 3 months; they used acrylic mould for self dilatation for 2 months ${ }^{5}$. Pardeshi R et al used amnion grafts and surgicel in vaginoplasty. They used surgicel for raw area repair following amnion grafting ${ }^{6}$.

\section{Conclusion}

At the advent of emerging modern technology in medical science, there is an inclination of most of the surgical procedure towards minimally invasive procedure but in the case of vaginal agenesis the conventional methods like modified Mc Indoe's are still remains the gold standard. At the same time regarding the essential components of the procedure, grafting material - amnion is found to be most effective, easily available, soft, cheap and with little side effects. There is scope of further evaluation of the procedure by large number of multicentric studies.

\section{Conflict of interest: None. Disclaimer: Nil.}

\section{References}

1. Breech LL, Roock JA, Jones HW, Rock JA, editors. Telindes's operative Gynaecology. 11th Edition. Philadelphia: Wolters Kluwer. 2015: p.516-20.

2. Tancer ML, Kaiz M, Veridiano NP. Vaginal epithelializattion with human amnion. Obstec Gynecol. 1979; 54: 345.

3. Karjalainen O, Myllynenl O, Kajanoja P, Tenhunen A., Purola E, Timonen S. Management of Vaginal agenesis. Ann Chir Gynaecol. 1980; 69: 37- 41.

4. Sarwar I, Sultana R, Nissa RU, Qayyum I. Vaginoplasty by using Amnion graft in patients of Vaginal agenesis Associated with MRKS. J Ayub Med Coll Abbottabad. 2010. 22(1): 7-10

5. Kathpalia SK. Creating neovagina using amnion. Med J Armed Forces India. 2016 Dec;72(Suppl1) : 120-2.

6. Pardeshi R, Meenna K, Gurjan K. Use of Amnion graft and surgery in Vaginoplasty for secondary vaginal atresia - A case report. Nigerian J Plastic Surgery.2019.15:24-6. 